\title{
La crítica literaria periodística como herramienta didáctica en la Facultad de Magisterio
}

\section{Journal's literary criticism as a didactic tool in the Faculty of Education}

\author{
ARÁNZAZU BEA \\ UNIVERSITAT DE VALÈNCIA \\ CARMEN RODRÍGUEZ GONZALO \\ UNIVERSITAT DE VALÈNCIA
}

Recibido: 28/02/2014

Aceptado: 15/05/2014

ABSTRACT: Jounal's literary criticism -a complex and flexible genre that combines exposition and argumentation, description and evaluation and that is subjected to strict space limitations- can be a useful linguistic and literary teaching resource at faculties of education.

The design of the didactic sequence (SD) «Literary criticism as an argumentative text», and its implementation in the first year course at the Faculty of Education of the Universitat de València Spanish Language for Teachers, has enabled us to value the opportunities that this genre offers for teaching-learning languages and to help students become familiar with the it. Learners can find literary criticism this useful in their teaching activities, since it can provide them with some criteria to identify quality literature.

This paper belongs to the research on the teaching of writing processes and metalinguistic activity, as described by Ruiz and Camps (2009).

Keywords: argumentation, literary criticism, didactic sequence, action research.

RESUMEN: La crítica literaria periodística -género complejo y flexible que combina exposición y argumentación, descripción y valoración, y que se somete a estrictas limitaciones de espacio- puede resultar un recurso didáctico lingüístico y literario útil en Magisterio.

El diseño de la secuencia didáctica (SD) «La crítica literaria como texto argumentativo» y su posterior implementación en la asignatura de Lengua española para maestros de primero de Magisterio, nos ha permitido valorar las posibilidades que el género ofrece para la enseñanza-aprendizaje de la lengua, como herramienta útil para la labor 
docente, ya que puede proporcionar a los futuros maestros criterios para identificar la literatura de calidad.

Este trabajo se inscribe en la línea que investiga la didáctica de los procesos de escritura y de la actividad metalingüística (Ruiz y Camps, 2009).

Palabras clave: argumentación, crítica literaria, secuencia didáctica, investigaciónacción.

\section{Introducción y objetivos}

Desde hace décadas, la escritura se ha convertido en objetivo de investigación y en prioridad educativa. El fundamento teórico actual de la enseñanza de la escritura responde a dos grandes presupuestos (Rodríguez Gonzalo, 2005): escribir es una actividad social -porque tiene un propósito comunicativo y porque es una construcción colectiva: para comunicar por escrito, elegimos los géneros o formas sociales establecidas para ello-, y escribir es un proceso complejo en el cual han de tenerse en cuenta tres grandes etapas: la planificación, la textualización y la revisión.

Dada su complejidad, la enseñanza-aprendizaje de la escritura merece una atención especial, porque no consiste solo en la transmisión de conocimientos lingüísticos, sino que necesariamente supone el desarrollo de unas habilidades que requieren esfuerzo y entrenamiento, sobre todo si nos referimos a la escritura que transforma el conocimiento (knowledge-transforming) (Bereiter y Scardamalia, 1987) y no únicamente a decir el conocimiento (knowledgetelling). A diferencia de este último tipo de escritura -cuya estructura básica depende de los procesos de recuperación de contenidos de la memoria- la escritura que transforma el conocimiento supone fijar metas, objetivos, que han de conseguirse mediante el proceso de composición. De hecho, Bereiter y Scardamalia critican la educación que fomenta el tipo más pasivo de cognición, la que dice a los estudiantes lo que tienen que hacer, en lugar de animarlos a seguir sus intereses e impulsos espontáneos, y añaden que la capacidad para luchar y resolver los problemas de contenido y retóricos remite a un proceso dialéctico de reflexión. Desde esta perspectiva, el docente ya no es un transmisor, sino que se convierte en un mediador entre el alumno y el conocimiento (Ríos y Salvador, 2008). 
Tanto Bereiter y Scardamalia como Flower y Hayes $(1980,1981)$-quienes comparan lo que hacen los autores cualificados y los no cualificados cuando componen un texto- se refieren a la escritura en una primera lengua y han servido de base teórica para la aproximación a la enseñanza-aprendizaje de la escritura en L1 y en L2. Mediante la incorporación de actividades de pre-escritura, como la lluvia de ideas, la elección de temas personalmente significativos, la instrucción de estrategias en las etapas de composición, redacción, revisión y edición y la elaboración de varios borradores, la enseñanza-aprendizaje de la escritura tiene en cuenta lo que hacen los autores cuando escriben. La atención a la escritura como proceso requiere $-\mathrm{y}$ fomenta- la interacción en el aula y estimula a los estudiantes para que analicen y comenten textos diversos.

En este trabajo hemos fijado el objetivo en la enseñanza-aprendizaje de un género discursivo concreto, la crítica literaria, para lo cual hemos diseñado una secuencia didáctica (SD) que hemos implementado con alumnos de primero de Magisterio. ${ }^{1}$ La secuencia didáctica es un tipo de proyecto de trabajo específico de lengua y literatura que responde al enfoque comunicativo de la enseñanza de las lenguas:

[...] partiendo del postulado de que todo depende de las necesidades lingüísticas de los alumnos, esta metodología concibe la lengua como un instrumento de comunicación o interacción social y considera las dimensiones lingüísticas y extralingüísticas que constituyen un saber-hacer, a la vez verbal y no verbal. Se trata de un conocimiento práctico del código y de las reglas psicológicas, sociológicas y culturales que permitirán su apropiado empleo en situaciones cotidianas. (Dolz, Gagnon y Mosquera, 2009: 133)

Efectivamente, la secuencia didáctica parte de los textos iniciales (producciones iniciales), que muestran el grado de conocimiento del género discursivo que tienen los estudiantes, información que permite ajustar el diseño de la intervención a la realidad del aula. El hecho de que se aborde la enseñanza de un género discursivo concreto -inscrito en un ámbito social, con una intención comunicativa específica y unas características que lo definen-, evidencia que la SD es una herramienta didáctica que integra lo lingüístico y lo extralingüístico, que se sitúa en la intersección entre la investigación sobre la didáctica de los procesos de escritura y sobre la actividad metalingüística y la enseñanza de la gramática, tal como lo enun-

1. Este estudio es parte del proyecto de investigación «Dificultats d'escriptura amb textos argumentatius i explicatius i intervenció didàctica. Una aproximació des de tres llengües» (N/Referencia: UV-INV-AE11-42019), realizado por el grupo GIEL en 2012. La implementación de la SD se llevó a cabo con alumnos de primero de grado, durante el curso 2011-2012, en la Facultat de Magisteri de la UV. 
cian Ruiz y Camps (2009). La estructura de la SD -los talleres en pequeños y en grandes grupos- fomenta el trabajo cooperativo e insiste en una de las fases clave de la escritura, la revisión, y la presenta como una fase que atraviesa el proceso y no únicamente como la etapa final (Carlino, 2004) (véase figura 1):

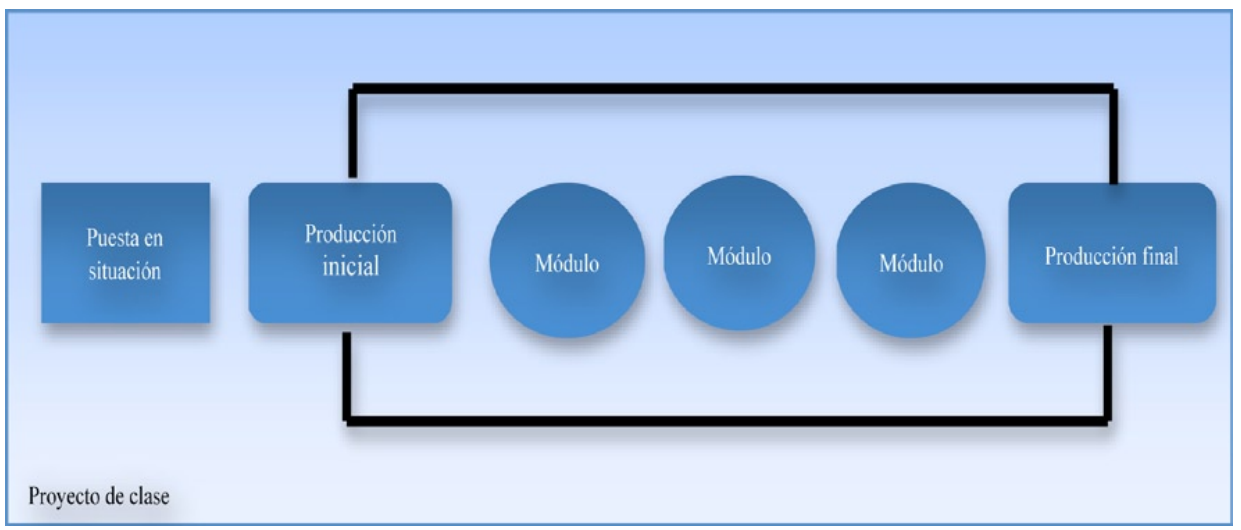

Figura 1. Esquema de secuencia didáctica (Dolz, Schneuwly, 2009: 3)

Los motivos de haber escogido la crítica literaria para esta secuencia didáctica son varios. Por una parte, es un género literario relativamente poco frecuentado desde el punto de vista didáctico ${ }^{2} \mathrm{y}$, sin embargo, podría resultar sumamente útil: si consiguiéramos que los estudiantes de Magisterio se familiarizaran con la crítica literaria -se acostumbraran a consultar periódicamente suplementos culturales y revistas de libros, sobre todo de literatura infantil y juvenil (LIJ), en papel o en la red-adquirirían herramientas para aprender a distinguir la LIJ de calidad de otros tipos de materiales de menor interés. Esto debería redundar en una selección más cuidada de las lecturas recomendadas en educación infantil y primaria, así como en una mejora de los fondos de las bibliotecas escolares. Este trabajo nos ha permitido analizar en qué medida los alumnos universitarios que han participado en la SD «La crítica literaria como texto argumentativo» se han familiarizado con este género discursivo complejo.

2. Aunque la crítica no es un género literario excesivamente frecuentado en la enseñanza -lo son más la narrativa o la poesía, por ejemplo-, sí que es cierto que la escuela ha abierto caminos hacia ella abordando géneros relacionados con la crítica literaria como las fichas de libros y las fichas de lecturas. 


\section{La crítica literaria como género discursivo}

Aunque el género de la «crítica literaria» presenta variantes -escritos más o menos extensos, más académicos y expositivos frente a otros más divulgativos y valorativos-, en el caso de la crítica literaria periodística, sujeta a menudo a la actualidad editorial y a la escritura por encargo con estrictas limitaciones de espacio, podemos afirmar que, en general, ha de cumplir dos funciones fundamentales: presentar una obra y valorarla; es decir, como lectores de una crítica literaria tendríamos que ser capaces de responder, al menos, a dos preguntas básicas: ¿nos hacemos una idea cabal de cómo es la obra comentada?, y ¿le ha gustado al crítico la obra que comenta? Estas dos cuestiones han servido de eje en el diseño y la implementación de la SD que presentamos.

La crítica literaria periodística es, sin duda, un género flexible formalmente: puede ser un texto cercano al retrato literario, que trence con delicadeza y precisión los rasgos biográficos del autor con las características artísticas de la obra -recordemos, por ejemplo, el Borges de los Prólogos con un prólogo de prólogos ${ }^{3}$ o los Prólogos a la Biblioteca de Babel-; puede consistir, sobre todo, en un análisis minucioso de un libro que, además, se esfuerce en mostrar los vínculos que mantiene con otros autores o con determinadas corrientes literarias -Harold Bloom (2000), Cyril Connolly (2005), Edmund Wilson (2008)-; puede predominar la intención divulgativa como es el caso de Marcel Reich-Ranicki (2000 y 2006), que aboga por una crítica que se sitúe entre el entusiasmo, el enfurecimiento y la reflexión y con un necesario didactismo, dado que se dirige a un lector no especializado, propio de la prensa: ha de tener referencias eruditas, ha de combinar análisis y reflexión. De las palabras de Reich-Ranicki, se deduce la presencia de la subjetividad en este género, subjetividad que también evidencia, por ejemplo, Edith Wharton, cuando afirma que «La crítica es tan persistente como una sustancia radioactiva [...]. No hay modo de reaccionar ante ningún fenómeno si no es criticándolo, y diferenciar y complicar las propias reacciones es un divertimento al que la inteligencia humana probablemente nunca renunciará» (Wharton, 2012: 28).

Por este motivo, muchos autores han coincidido en concebir la crítica literaria como un género con puntos de contacto con la llamada literatura del yo:

3. En las referencias bibliográficas, aparece entre corchetes la fecha de la publicación original; cuando el volumen consultado no es una reedición -ni una traducción- de un único título, sino una selección de artículos de distintas procedencias y fechas, aparece entre corchetes el período temporal en que fueron publicados los textos originales recopilados en el volumen referenciado. 
si, parafraseando a Anne Fadiman (1998), nuestros libros han registrado el paso del tiempo y nos recuerdan todas las ocasiones en que los leímos y releímos, inmediatamente surge la idea de la crítica literaria como un género cercano al memorialístico: «En cuanto a la crítica, pienso que es una de las formas modernas de la autobiografía. [...] El crítico es aquel que reconstruye su vida en el interior de los textos que lee» (Piglia, 2001: 13). Es cierto, pues, que se critica desde el sujeto, desde su historia, sus conocimientos, sus «fòbies i fílies, no sols recomanables, sinó necessàries» (Mondria, 2002: 10), se critica desde una idea personal de la «gran literatura», al fin y al cabo «leemos -algo en lo que concuerdan Bacon, Johnson y Emerson- para fortalecer nuestra personalidad y averiguar cuáles son sus auténticos intereses» (Bloom, 2000: 18).

Compartimos con estos autores la concepción de la crítica literaria como un género cercano a la autobiografía, a la literatura del yo, que nos aporta las claves de una obra, de la cual nos ofrece una lectura particular, experta: «Según he llegado a entenderla, la crítica literaria no debería ser teórica, sino empírica y pragmática. Los críticos que considero mis maestros -en particular, Samuel Johnson y William Hazlitt- practican su arte a fin de hacer delicadamente explícito lo que en un libro hay de implícito» (Bloom, 2000: 14). Un crítico intenta explicar lo que cualquier persona hace cuando lee (Woolf, 2009). Para Nabokov, el lector ha de detenerse en los detalles, «acariciarlos»; «el buen lector es aquel que tiene imaginación, memoria, un diccionario y cierto sentido artístico... sentido que yo trato de desarrollar en mí mismo y en los demás siempre que se me ofrece la ocasión» (Nabokov, 2010: 12). Y añade: «utilizo la palabra lector en un sentido muy amplio. Aunque parezca extraño, los libros no se deben leer: se deben releer. Un buen lector, un lector de primera, un lector activo y creador, es un «relector»»" (Nabokov, 2010: 12). Creemos que el conocimiento, la lectura y la práctica de la crítica literaria pueden contribuir, de alguna manera, a formar «relectores».

\section{Metodología}

La manera de acercar la crítica literaria a los estudiantes de Magisterio -género que se inscribe en la llamada argumentación social, «de interés didáctico para las prácticas discursivas en el aula» (Rodríguez Gonzalo, 2012)- fue, como explicamos en la introducción, con el diseño de la secuencia didáctica «La crítica literaria como texto argumentativo», los alumnos escribieron una crítica literaria (producción inicial, TI) y, tras los talleres, redactaron una segunda crítica (producción final, TF) (véase figura 2): 


\section{Talleres SD «La crítica literaria como texto argumentativo»}

Taller 1: Reconocimiento del género.

Lectura y comentario de críticas literarias publicadas en varios medios («Babelia» de El País, «Culturas» de La Vanguardia, revista Faristol).

Realizado en gran grupo.

Finalidad (para qué): dar las claves de una obra y de su autor y valorarlos.

Ámbito de uso (dónde se pueden encontrar): suplementos culturales de periódicos, revistas de literatura.

Taller 2: Elementos de una crítica. Selección y organización de la información.

Realizado en pequeños grupos.

Leer, localizar y comentar en varias críticas los elementos siguientes:

- Título y ficha de la obra

- Tipos de comienzo de las críticas

- Terminología específica

- Cómo se proporciona la información sobre el autor

- Cómo se describe la obra comentada y cómo se relaciona con otras obras del mismo autor o de otros autores

- Uso de citas literales (del autor comentado o de otros autores sobre esa obra o sobre ese autor)

Taller 3: Elementos de una crítica. Selección y organización de la información.

Puesta en común en gran grupo.

Cada grupo expuso el trabajo al resto de la clase, que aportaba detalles o discutía los comentarios si no los consideraba acertados o si detectaba algún elemento clave que no se hubiera mencionado.

\section{Figura 2. Esquema de los talleres de la SD «La crítica literaria como texto argumentativo»}

Durante los talleres, los alumnos percibieron que a menudo las críticas comenzaban presentando al autor o también, pero menos frecuentemente, situando el título en concreto en el conjunto de la obra de ese autor. También comprobaron que la valoración de la obra no aparecía expresada en términos de «me gusta» o «no me gusta»-aunque ese fuera el sentido-, sino que la detectaban en adjetivos, verbos y sustantivos concretos. Un aspecto importante fue 
cuando los estudiantes se dieron cuenta de que rara vez un comentario era absolutamente halagador o negativo respecto a la obra y al autor reseñados, sino que lo más habitual era que, a pesar de detectar que el libro había gustado al crítico, este solía mencionar algún aspecto no del todo logrado; $\mathrm{y}$, al contrario, a pesar de que el crítico denunciaba que el título no tenía calidad, era capaz de valorar algún rasgo positivo. Esto resultó un verdadero descubrimiento para los alumnos que, en su mayoría, tendían a la incondicionalidad en sus TI.

Los estudiantes aprendieron a plantearse, ante sus textos, las dos preguntas clave que debe responder toda crítica y percibieron que las distintas partes -información sobre el autor, sobre la obra y la valoración-no aparecieran como fragmentos independientes unos de otros; fueron conscientes de que valorar a través del léxico resultaba más costoso que hacerlo en primera persona con un simple «me gusta» o «no me gusta». También se dieron cuenta de que en toda crítica aparece la ficha del libro comentado y casi siempre, un título sugerente y atractivo. Algunos se fijaron en los destacados y en otros detalles de la edición periodística (fotografías, pie de foto, ladillos, despieces, etc.).

Tanto en los TI, como en los TF, hemos clasificado los problemas en dos grandes apartados:

a) Cuestiones que tienen que ver con el género discursivo, que incluyen desde aspectos que podríamos llamar «externos», como el título y la ficha de la obra, hasta aspectos «estructurales», como si aparece o no información del autor, si se proporciona una idea cabal del libro comentado (género literario, resumen, estructura, etc.), si se utilizan citas (del autor en cuestión o de otros autores), y si se valora la obra o no y cómo se valora (aspectos de modalización): en qué persona, si la valoración se integra en el resto del comentario o se redacta en un párrafo aparte, si el alumno es capaz o no de opinar a través del léxico o si emplea recursos más sofisticados como la ironía.

b) Cuestiones generales del nivel textual, relacionadas, sobre todo, con la coherencia (cantidad de información, distribución en párrafos, frases ininteligibles) y la cohesión (problemas de pronominalización, de uso de preposiciones, de concordancia sujeto-verbo, de omisión del sujeto de modo incorrecto), pero también con la gramática en general (usos incorrectos del gerundio, problemas de léxico - palabras comodín, imprecisiones, repeticiones-) y la ortografía.

A continuación, abordaremos el punto $a$ ), es decir, los problemas y avances que se refieren al género discursivo de la crítica literaria y que hemos esquematizado del modo siguiente: 
- 27 producciones iniciales $(\mathrm{TI})^{4}$

- Talleres:

- Preguntas clave

¿Nos hacemos una idea cabal de la obra comentada?

¿Le ha gustado al crítico la obra?

- Elementos específicos del género

Título y ficha

Comienzos

Información del autor

Descripción/resumen/estructura de la obra

Citas literales

Valoración mediante el léxico $\rightarrow$ Opinión matizada, no monolítica

- 28 producciones finales $(\mathrm{TF}) \rightarrow 23$ válidos $^{5}$

\section{Análisis, discusión de resultados}

Con el fin de ver cómo y en qué aspectos del proceso de enseñanza de la escritura ha influido la implementación de esta secuencia didáctica, hemos comparado las producciones iniciales $(27 \mathrm{TI})$ y finales $(28 \mathrm{TF} \rightarrow 23 \mathrm{TF})$ de los alumnos, tras lo cual hemos focalizado el análisis en los escritos de 12 alumnos ( 24 textos). Hemos intentado que esta muestra -aproximadamente un $43 \%$ del total- sea representativa, de manera que hemos elegido alumnos con distintas características y resultados diferentes. La producción inicial ha sido el criterio para clasificar los alumnos en tres grupos, según partieran de una competencia escrita muy buena -sin problemas en el nivel textual, escritos coherentes, cohesionados y gramaticalmente correctos- (grupo A: 8, 10, 23 y 27), aceptable -con errores, sobre todo, de corrección gramatical- (grupo B: 7, 9, 16 y 19) o con problemas graves de coherencia -incorrecta distribución de la información en párrafos, frases ininteligibles-, cohesión -omisión incorrecta de sujetos, errores de pronomi-

4. Para preservar el anonimato de los 32 alumnos que participaron en esta SD, han sido numerados del 1 al 32; por estar ausentes al comenzar las clases y por otras incidencias, cinco estudiantes no entregaron su producción inicial $(4,11,15,17$ y 28$)$; por tanto, partimos de 27 TI.

5. Se entregaron $28 \mathrm{TF}$; de estos $28 \mathrm{TF}$, cinco eran plagios íntegros-o casi-de distintos comentarios e informaciones que circulan por internet. Este hecho no afecta al análisis de lo que hemos denominado «elementos externos»-título y ficha-, pero sí puede confundir los resultados del resto del análisis, así que, en lo que se refiere a las «cuestiones estructurales», no hemos tenido en cuenta estos cinco trabajos (TF n. ${ }^{\circ} 1,14,22,28,31$ ) y, por tanto, hablaremos de $23 \mathrm{TF}$. 
nalización, de concordancia sujeto-verbo- y corrección gramatical, que llegaban a dificultar la comprensión del escrito (grupo C: 2, 5, 18 y 26).

La razón de haber seleccionado esta muestra tiene que ver, sobre todo, con el hecho de que manifestar la opinión por escrito es una tarea que pone en funcionamiento numerosos procedimientos -en su mayoría relacionados con la modalización-; el análisis de esta cuestión implica, a su vez, tratar conjuntamente elementos diversos que suelen aparecen en diferentes partes del escrito -a veces, salpicados por todo el texto. Abordar esta cuestión en toda su amplitud y en todos sus matices podría ser el tema de otro estudio; en este trabajo, pues, nos centraremos en la comparación de los 24 textos (12 TI y $12 \mathrm{TF}$ ) de los doce alumnos seleccionados y agrupados en conjuntos de cuatro en los grupos A, B y C.

En las tablas comparativas siguientes (véanse las figuras 3 y 4), hemos resumido los resultados que comentamos a continuación, aquellos datos que pueden ser cuantificados o que pueden describirse mediante la presencia («sí») o ausencia («no») en los escritos de los alumnos. Por supuesto, los datos numéricos y los que hemos descrito con los valores «sí/no» han de ser necesariamente matizados y complementados con las reflexiones y ejemplos que incluimos tras las tablas. Con todo, creemos que estos resúmenes numéricos ofrecen una visión general de los resultados.

\begin{tabular}{|c|c|c|}
\hline & producciones iniciales (TI) & producciones finales (TF) \\
\hline Con título & $0 / 27$ & $21 / 28$ \\
\hline Con ficha del libro & $1 / 27$ & $23 / 28$ \\
\hline $\begin{array}{l}\text { Con información } \\
\text { sobre el autor }\end{array}$ & $\begin{array}{l}\text { 10/27, de los cuales: } \\
\text { - } 6 \text { con información muy } \\
\text { breve } \\
\text { - } 4 \text { con información más } \\
\text { sólida pero siempre ofre- } \\
\text { cida de manera desligada } \\
\text { del resto del texto (en } \\
\text { párrafo aparte). }\end{array}$ & $\begin{array}{l}\text { 21/23, de los cuales: } \\
\text { - } 12 \text { con la información } \\
\text { desvinculada de la obra y } \\
\text { en párrafo aparte } \\
\text { - } 9 \text { con la información vin- } \\
\text { culada con la obra ( } 3 \text { de } \\
\text { ellos en párrafo aparte). }\end{array}$ \\
\hline $\begin{array}{l}\text { Con inclusión de } \\
\text { citas }\end{array}$ & $3 / 27$ & $\begin{array}{l}6 / 23 \\
\text { (el porcentaje aumenta } \\
\text { del } 11 \% \text { al } 26 \% \text { ) }\end{array}$ \\
\hline
\end{tabular}

Figura 3. Tabla comparativa general sobre aspectos del género discursivo 


\begin{tabular}{|c|c|c|c|c|c|c|c|c|c|}
\hline & \multirow[b]{2}{*}{ N. ${ }^{o}$} & \multicolumn{4}{|c|}{ PRODUCCIONES INICIALES (TI) } & \multicolumn{4}{|c|}{ PRODUCCIONES FINALES (TF) } \\
\hline & & Título & Ficha & Autor & Citas & Título & Ficha & Autor & Citas \\
\hline \multirow{4}{*}{ 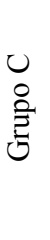 } & 2 & No & No & Sí & No & No & No & Sí & Sí \\
\hline & 5 & No & No & No & No & No & No & Sí & No \\
\hline & 18 & No & No & Sí & No & Sí & Sí & Sí & Sí \\
\hline & 26 & No & No & No & No & No & Sí & Sí & Sí \\
\hline \multirow{4}{*}{ 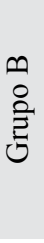 } & 7 & No & No & No & Sí & Sí & Sí & Sí & Sí \\
\hline & 9 & No & No & No & No & Sí & No & No & No \\
\hline & 16 & No & No & No & No & Sí & No & Sí & Sí \\
\hline & 19 & No & No & No & No & Sí & Sí & Sí & Sí \\
\hline \multirow{4}{*}{$\begin{array}{l}\varangle \\
\stackrel{0}{\Xi} \\
\stackrel{\Xi}{\Xi}\end{array}$} & 8 & No & No & No & No & Sí & Sí & Sí & Sí \\
\hline & 10 & No & No & Sí & Sí & Sí & Sí & Sí & Sí \\
\hline & 23 & No & No & Sí & No & Sí & Sí & Sí & Sí \\
\hline & 27 & No & No & No & No & Sí & Sí & Sí & No \\
\hline
\end{tabular}

Figura 4. Tabla comparativa sobre aspectos del género discursivo de los doce alumnos seleccionados

En la tabla de la figura 4, aparecen con fondo claro y con el indicativo de ausencia «No» las carencias o errores y con fondo más oscuro y con el indicativo de presencia «Sí», los avances: como puede apreciarse, el fondo claro predomina en las producciones iniciales (TI) y el oscuro en las finales (TF). El modo en que los alumnos han valorado la obra no es una cuestión cuantificable, por lo que la describiremos y ejemplificaremos, tras comentar los rasgos que aparecen en las tablas anteriores.

El análisis de los textos iniciales (TI) revela que, en su mayoría, los alumnos desconocían las características genéricas de una crítica literaria; sin embargo, en muchos casos mostraron que sí poseían una idea más o menos remota y confusa de lo que significaba valorar una obra. Muchos estudiantes relacionaban acertadamente "crítica» con opinión, que a menudo formulaban en primera persona y con enunciados muy sencillos del tipo «me ha gustado» $\mathrm{o}$ «no me ha gustado» en un párrafo aislado y final. Algunos alumnos dieron un salto cualitativo, confundieron manifestar una opinión con «contar la vida»e incluyeron aspectos privados de su cotidianidad que exceden los límites de este 
género. En el otro extremo aparecen quienes redactaron un texto expositivo: resumieron la obra pero no proporcionaron ninguna valoración.

Título y ficha. En cuanto a los aspectos externos -título y ficha-, llama la atención que ninguno de los 27 textos iniciales lleve título y solo uno de ellos incluya la ficha (el 24). Este hecho contrasta con lo que sucede en los 28 escritos finales: solo siete se entregaron sin título $(2,5,15,25,26,29,32)$, es decir solo un $25 \%$ de los textos finales no tiene título -frente al $100 \%$ de los TI-; y únicamente cinco producciones finales aparecen sin ficha $(2,5,15,16 \mathrm{y}$ 31 ), es decir, menos del $18 \%$ (el 17,9\%) de los alumnos no incluyó la ficha en su crítica final.

Pero los cambios no son solo cuantitativos: varios alumnos fueron capaces de titular de manera original y la originalidad es un síntoma de que los estudiantes se han apropiado del género discursivo, lo han hecho suyo y, por tanto, se sienten suficientemente seguros como para innovar. Así encontramos, entre otros, títulos como los siguientes:

- «Mujercitas: un ejemplo de austeridad» (TF3, sobre Mujercitas, de Louisa May Alcott);

- «Civilización o barbarie: la eterna pugna del ser humano» (TF8, sobre El señor de las moscas, de William Golding);

- «Rara avis» (TF9, sobre El guardián entre el centeno, de J. D. Salinger);

- «Una de piratas» (TF18, sobre La isla del tesoro, de Stevenson);

- «Ni a mis peores enemigos» (TF23, sobre Pelo de zanahoria, de Jules Renard).

Estos primeros datos sobre los aspectos más externos de los escritos de los alumnos, apuntan ya hacia la notable evolución que supuso la implementación de la SD «La crítica literaria como texto argumentativo» en los textos finales de los estudiantes.

Conviene recordar aquí que, de las 28 producciones finales, cinco son plagios íntegros -o casi- de distintos comentarios e informaciones que, sobre esas obras, circulan por internet. Este hecho no afectaba al análisis de los elementos externos - título y ficha-, pero sí puede distorsionar los resultados del resto del análisis, así que, en adelante, en lo que se refiere a las cuestiones estructurales, dejaremos de lado estos cinco trabajos $(1,14,22,28,31)$ y hablaremos de 23 TF.

Información sobre el autor. Cuando observamos lo que hemos denominado aspectos estructurales del género de la crítica literaria, de nuevo se evidencia que, salvo alguna excepción, la gran mayoría de Ti (17, casi un $63 \%$-un 62,9\%-) 
no proporciona dato alguno sobre el autor de la obra comentada (uno ni siquiera lo menciona); seis incluyen alguna información, aunque muy breve $(8,12$, $16,19,21$ y 23 ; un 22,2 \%) y solo cuatro alumnos consideraron importante hablar del escritor o escritora $(2,14,10$ y 18; un 14,8\%), aunque todos lo hacen de manera desligada del resto (en párrafo o párrafos independientes).

Los TF, sin embargo, a menudo ofrecen la información sobre el autor integrada en la reseña, jerarquizando aquellos datos y circunstancias vitales que tienen que ver con la obra comentada. De los 23 TF considerados válidos, solo dos no aportan ningún dato sobre el autor (12 y 29, un 8,7 \%, frente a los 17 TI, casi un $63 \%$ ); doce proporcionan esta información de manera desvinculada de la obra y en párrafo aparte $(2,3,5,9,15,19,20,21,25,26,30$ y 32) y nueve la vinculan con la obra $(6,7,8,10,16,18,23,24$ y 27). Veamos un ejemplo que no ofrecía información del autor en TI y, en TF, la ofrece y, además, vinculada con la obra e integrada en el texto:

Se trata de una novela con componentes autobiográficos: Louisa tenía tres hermanas, Anna, Lizzie y Abba May y, al igual que las cuatro hermanas de su novela, recibieron la educación en su propio hogar, como en el caso de las pequeñas de la familia March: Amy y Beth.

Después del inicio de la Guerra Civil Americana (sic), esta autora se hizo enfermera voluntaria, lo que la llevó a sufrir fiebres tifoideas, que más tarde le trataron con calamina. Este tratamiento, que conllevó un envenenamiento de mercurio, le hizo padecer numerosos males durante toda su vida. En este sentido podemos observar también cierto parecido a la novela, ya que una de las hermanas, Beth, es contagiada de escarlatina por un niño de una familia pobre a la que ella prestó ayuda, enfermedad de la que no acaba de recuperarse por completo y que finalmente acaba matándola.

Louisa pasó la mayor parte de su vida en Boston y Concord, Massachussets, de ahí la presentación geográfica de la familia March. Ciertamente, pienso que es gracias a eso que la ambientación del libro es tan rica en detalles. (TF16, sobre Mujercitas, de Louisa May Alcott)

Inclusión de citas. Únicamente tres alumnos incluyen citas literales de la obra comentada (un 11,1\%) en TI, pero el TI 20 es el único que logra integrar de manera fluida, sin brusquedades, una cita literal de la obra comentada.

Como puede verse en la figura 3, en los TF se duplica el número de alumnos que utilizan este recurso eficazmente, (6 textos de 23 , por lo que el porcentaje crece de un $11,1 \%$ a un $26,1 \%$ ). Veamos, como ejemplo, el caso 7 , uno de los pocos que utiliza las citas en TI y en TF, pero con una notable evolución: 
Seguidamente, algunas frases y fragmentos del libro que, en mi opinión, son importantes e impactantes y que se merecen una mención son, en primer lugar: «Pero mientras lo pensaba, sus piernas que no paraban de moverse, lo iban acercando más y más a aquel punto, que entretanto se habia convertido en una manchita [...] a medida que Bruno se acercaba más, vio que aquella cosa no era ni un borrón ni un punto ni una manchita, sino una persona. $Y$ aquella persona era un niño». En este fragmento podemos observar el primer encuentro de ambos niños, que más tarde se convertiría en una gran amistad. (La cursiva es del original) (TI7, sobre El niño con el pijama de rayas, de John Boyne)

El autor explica de forma muy detallada los rasgos, las emociones, la personalidad, las cosas y las situaciones, lo que permite visualizarlo todo desde una perspectiva muy completa: «Su propia voz pareció un murmullo tras la áspera nota de la caracola. La apretó contra sus labios, respiró fuerte y volvió a soplar. De nuevo estalló la nota y, bajo un impulso más fuerte, subió hasta alcanzar una octava y vibró como una trompeta... (TF7, sobre El señor de las moscas, de William Golding)

Es importante señalar que el uso relevante e integrado de citas literales demuestra un grado elevado de complejidad y de reflexión en la escritura, así como mayor atención a la revisión de los escritos. Y, aunque los alumnos del grupo A lo incorporan con mayor fluidez y frecuencia en sus textos (TF8 y 10), también lo utilizan los alumnos del grupo B (TF7, 16 y 24) e, incluso, alguno de los estudiantes que mayores problemas presentaban en la escritura (TF2). De todos ellos, cinco no lo habían usado en su producción inicial $(2,8,10,16$ y 24), es decir, que lo incorporaron a partir del trabajo en la intervención didáctica y el n. ${ }^{\circ}$, que sí había usado este recurso en su TI pero de manera rígida y forzada, ahora lo integra con mayor naturalidad y eficacia en su escrito.

Valoración de la obra comentada.- Otro aspecto realmente destacable -quizá el más importante porque se relaciona con la esencia misma de la crítica literaria, con la opinión, la visión personal y razonada sobre la obra comentada- es la evolución que muestran las producciones finales respecto a las iniciales en cuanto a la valoración del libro que tratan. Aquí se han tenido en cuenta factores como el abandono de la primera persona del singular $-\mathrm{O}$ su matización- y la sustitución de fórmulas simples como «me ha gustado» o «no me ha gustado» por redacciones más complejas que van desde el uso de un léxico valorativo hasta la utilización de recursos tan sofisticados como la ironía. Además, desaparece la información excesivamente personal, íntima, de algunos alumnos que alejaba el texto de este género discursivo y aparece la originalidad, sobre todo en los principios y algunos finales de los escritos. Veamos, en esquema, esta evolución (figura 5): 


\section{Problemas en TI}

- Sin opinión $\rightarrow$ Texto expositivo

- Desvinculada del resto del texto $\rightarrow$ párrafo final

- En primera persona y con fórmulas simples $\rightarrow$ «me ha gustado», «no me ha gustado»

- Información excesivamente personal $\rightarrow$ confusión entre manifestar la opinión y relatar acontecimientos tan personales que no se adecúan al género de la crítica

\section{Avances en TF}

- Con opinión personal y matizada

- Integrada en el texto

- En primera persona del plural y/o uso de la impersonalidad $\rightarrow$ abandono fórmulas simples

- Sin información excesivamente personal

- Aparece la ironía y la originalidad

Figura 5. Valoración de la obra comentada: cuadro comparativo de problemas en TI $y$ avances en TF

\section{Comparemos algunos casos:}

Valoración: fórmulas simples/abandono de las fórmulas simples: «Esta primera introducción del libro es la parte que menos me gusto, (sic) porque se hace un poco pesada ya que te describe todo. [...]

Esta historia mezcla muy bien el pasado que nos cuenta la escritora Vida Winter, con el presente que vive la joven Margaret. Me gusta (sic) sobre todo los misterios que van surgiendo a ( $\mathrm{sic}$ ) cada capítulo que lees y como ( $\mathrm{sic}$ ) la autora a (sic) conseguido hacer que sigas el hilo de los sucesos...». (TI18, sobre El cuento número 13, de Diane Setterfield)

«Piratas, barcos, capitanes, patas de palo, loros, pero sobre todo un tesoro, son los ingredientes necesarios para hacernos pasar un buen rato como hace R. L. Stevenson (sic) (Edimburgo, Escocia) en La isla del Tesoro. Esta novela está inspirada en los viajes que este escritor debía hacer por culpa de su enfermedad, tuberculosis, que le obligaba ir (sic) a lugares donde el clima fuera más favorable para él». (TF18, sobre La isla del tesoro, de Robert Louis Stevenson)

Ironía y originalidad:

«Defendía Rousseau que el hombre es bueno por naturaleza y es la sociedad la que le corrompe. Y William Golding parece que no se quedó muy satisfecho con tamaña afirmación, se puso manos a la obra y alumbró El Señor de las Moscas ( sic)». ( $\mathrm{TF} 8$, sobre El señor de las moscas, de William Golding) «No, no le desearía ni a mis peores enemigos que les tocara como madre a la Señora Lepic. La historia que Jules Renard nos narra a partir de todo tipo de 
textos, desde relatos hasta cartas o apuntes, se puede considerar una historia de infelicidad sin tregua. Reflejo fiel de la vida del autor, la obra reproduce una analogía casi exacta de su infancia, incluso el mote con el que «cariñosamente» le reclamaban sus padres era el mismo que el del protagonista». (TF23, sobre Pelo de zanahoria, de Jules Renard)

\section{Conclusiones y prospectiva}

En el apartado anterior -análisis y discusión de resultados-se apuntan algunas de las conclusiones generales de este trabajo, a saber: que la secuencia didáctica es una vía metodológica eficaz para aunar reflexión metalingüística y uso de la lengua (Duran, 2010); que las mejoras en los escritos de los alumnos son notables y numerosas sobre todo en el nivel discursivo y, aunque también hay avances en el nivel textual, son menos evidentes; y que la razón de la efectividad de la secuencia didáctica radica en su propia definición y estructura: se trabaja un género discursivo en particular, lo cual sitúa la experiencia de la escritura en un contexto comunicativo concreto -se escribe pensando en una situación comunicativa, en una intención y un receptor-; además, el diseño de la secuencia parte de las producciones iniciales de los alumnos, que ayuda a modelar y matizar la intervención según los conocimientos y problemas de los estudiantes con los que se implementa la intervención.

La eficacia de la SD se percibe en todos los grupos de alumnos (A, B y C): los alumnos que partían con un buen nivel de expresión escrita, interiorizan las características del género (uso de la ironía, originalidad, descripción y valoración integradas). Los alumnos que mostraban menor competencia escrita también incorporan las características del género, pero tienen mayores dificultades para fusionar descripción y valoración: suelen mantener una primera parte de carácter expositivo (con información sobre el autor y la obra) y una segunda con la opinión personal sobre el libro comentado.

Cabría explorar más detenidamente los beneficios didácticos de la crítica literaria, sobre todo en el ámbito universitario, ya que creemos que puede ayudar a los estudiantes a aprender a escribir y a aprender a opinar. La escuela inicia el camino abordando las fichas de libros y las fichas de lecturas, pero el tratamiento didáctico del género podría consolidarse en los estudios superiores; creemos que la crítica literaria puede contribuir a la necesaria vinculación entre las áreas de Lengua y Literatura. 


\section{Referencias bibliográficas}

Bereiter, C.; M. Scardamalia (1987): The psychology of written composition, Hillsdale, Nueva Jersey: Lawrence Erlbaum Associates.

BLoom, H. (2000): Cómo leer y por qué. Trad. Marcelo Cohen, Barcelona, Anagrama.

Borges, J. L. (1998 [1923-1974]): Prólogos con un prólogo de prólogos, Madrid, Alianza.

- (2001 [1975-1985]): Prólogos de La Biblioteca de Babel, Madrid, Alianza.

Carlino, P. (2004): «El proceso de escritura académica: cuatro dificultades de la enseñanza universitaria», Educere, «Artículos arbitrarios», 26: 321327.

Connolly, C. (2005 [1929-1974]): Obra selecta. Trad. M. Aguilar, Barcelona, Lumen.

Dolz, J.; R. GaGnon; S. Mosquera (2009): «La didáctica de las lenguas: una disciplina en proceso de construcción», Didáctica (Lengua y Literatura), 21: 117-141.

Dolz, J.; M. Noverranz; B. SChNeuwly (2001): S'exprimer en français. Séquences didactiques pour l'oral et pour l'écrit, Bruselas-Ginebra, De Boeck-Corome.

Dolz, J.; B. Schneuwly (2009): «Escribir es reescribir. La reescritura en las secuencias didácticas para la expresión escrita», Leer.es.

Duran, C. (2010): «Les competències i l'ensenyament de la gramàtica», Articles de Didàctica de la Llengua i la Literatura, 51: 36-50.

Fadiman, A. (2000 [1998]): Ex Libris. Confesiones de una lectora. Trad. Isabel Ferrer Marrades, Barcelona, Alba.

Flower, L.; J. Hayes (1980): «The dynamics of composing: Making plans and juggling constraints» en GregG, L. W.; E. R. STEINBERg (eds.): $C o g$ nitive processes in writing, Hillsdale, NJ, Lawrence Erlbaum Associates, 31-50.

- (1981): «A Cognitive Process Theory of Writing», College Composition and Communication, 32: 365-387.

Mondria, A. (2002): «Qui critica al crític?», Avui, suplement «Cultura» 24/01/2002, 10.

Nabokov, V. (2010 [1980]): Curso de literatura europea. Trad. Francisco Torres Oliver, Barcelona, RBA.

Piglia, R. (2001 [1986]): Crítica y ficción, Barcelona, Anagrama.

Reich-Ranicki, M. (2000): Mi vida. Trad. José Luis Gil Aristu, Barcelona, Galaxia Gutenberg. 
- (2006): Los abogados de la literatura. Trad. J. L. Gil Aristu. Barcelona, Galaxia Gutenberg.

Ríos, I.; V. Salvador (2008): L'ensenyament del discurs escrit, Alzira, Bromera.

Rodríguez Gonzalo, C. (2005): Didáctica de la Lengua y la Literatura en la Educación Primaria. Proyecto docente, Valencia.

- (2012): «L'argumentació a l'aula: entre el raonament i l'opinió personal», Articles de Didàctica de la Llengua i la Literatura, 58: 8-19.

Ruiz, U.; A. Camps (2009): «Investigar los géneros discursivos en el proceso educativo», Revista de Psicodidáctica, 2 (vol. 14): 211-228.

Wharton, E. (2012 [1902-1938]). Criticar ficción. Trad. Amelia Pérez de Villar, Madrid, Páginas de Espuma.

WiLson, E. (2008 [1925-1972]): Obra selecta. Trad. A. Asutti, Barcelona, Lumen.

Woolf, V. (2009 [1916-1931]). El lector común. Trad. Daniel Nisa Cáceres, Barcelona, Lumen. 